DIW BERLIN

Discussion Papers

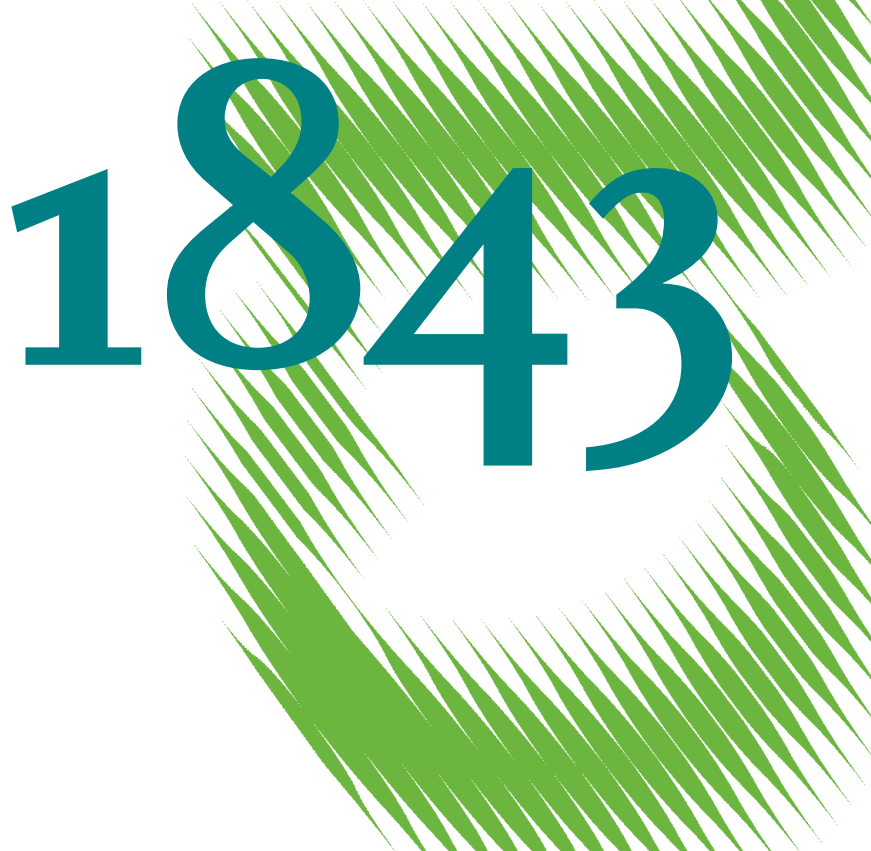

Merger Efficiency Gains: Evidence from a Large Transport Merger in France 
Opinions expressed in this paper are those of the author(s) and do not necessarily reflect views of the institute.

IMPRESSUM

(C) DIW Berlin, 2020

DIW Berlin

German Institute for Economic Research

Mohrenstr. 58

10117 Berlin

Tel. +49 (30) $89789-0$

Fax +49 (30) $89789-200$

http://www.diw.de

ISSN electronic edition 1619-4535

Papers can be downloaded free of charge from the DIW Berlin website:

http://www.diw.de/discussionpapers

Discussion Papers of DIW Berlin are indexed in RePEc and SSRN:

http://ideas.repec.org/s/diw/diwwpp.html

http://www.ssrn.com/link/DIW-Berlin-German-Inst-Econ-Res.html 


\title{
Merger Efficiency Gains: \\ Evidence from a Large Transport Merger in France ${ }^{1}$
}

\author{
Ariane Charpin ${ }^{2}$ \\ Joanna Piechucka ${ }^{3}$
}

January 7, 2020

\begin{abstract}
Many industries are seeing an increase in concentration, leading to a discussion on the effectiveness of horizontal merger enforcement. The policy debate shows that one of the key arguments put forward when supporting potential mergers is the possibility of realization of merger efficiency gains, specifically in the transport industry. Yet, there exists little empirical evidence on the actual effects of realized mergers on cost efficiencies. We exploit a large and highly debated merger that took place in the French transport industry to evaluate whether a merger between two major transport groups may give rise to merger efficiency gains. We exploit the industry setting to employ a difference-in-differences methodology evaluating the effect of the merger on operating costs of merging transport groups. Our results show that the merger did not lead to any merger specific efficiency gains for the merging parties. Our study relies on the use of several control groups and is robust to a great number of robustness checks as well as to the introduction of heterogeneous treatment effects, depending on the identity of the merging party, the contract type in place, as well as the closeness of competition of local operators. Overall, our study contributes to a growing number of case studies undertaken by economists that can help determine whether horizontal merger policy is being properly enforced.
\end{abstract}

Key words: Ex-post Evaluation; Mergers; Transport industry; Merger cost efficiencies.

JEL classification: C31, L40, L50, L92.

\footnotetext{
${ }^{1}$ We are extremely thankful to to CEREMA, GART and UTP for providing the complete database on urban public transport in France for the purpose of our research. We thank Sara Biancini, Philippe Choné, Tomaso Duso, Emmanuel Frot, Philippe Gagnepain, Marc Ivaldi, Dennis Rickert, Stéphane Saussier, Angelo Secchi, Joel Stiebale, Hannes Ullrich, Jean-Philippe Tropéano and Paola Valbonesi, as well as audiences at conferences and seminars at AFSE, CERNA, CRESSE, CREST, DIW Berlin, EARIE, JEI, JMA, YEM for their valuable comments.
}

${ }^{2}$ Economic Advisory, Deloitte France, acharpin@deloitte.fr.

${ }^{3}$ DIW Berlin, jpiechucka@diw.de. 


\section{Introduction}

The intensive merger activity observed since the 1990s along with speculation about the effectiveness of competition enforcement are fueling a growing interest in retrospective analyses of mergers. While there are a substantial number of studies estimating the price effects of large and/or controversial mergers, there exists little evidence on the effects of mergers on cost efficiencies. At the same time, efficiency gains are often one of the main arguments of merging parties in front of competition authorities and constitute, in theory, a central aspect to the economic motivation behind mergers. They constitute the primary justification as for why the mergers of competitors may benefit consumers. Not surprisingly, one of the "most important finding" of the report of Ormosi et al. (2015) providing a review of merger decisions in the European Union is that, "there is very little information on how dynamic factors, such as innovation and efficiencies, developed after a merger."

The objective of this study is to assess whether a merger between two major transport groups gave rise to efficiency gains. We do this by studying the effects on the operating costs of local urban public transport operators of a large merger that took place between two of the three leading urban transport groups in France. In 2009, Transdev selected Veolia Transport to merge. This merger was approved by the French Competition Authority in 2010 with remedies and the deal closed in 2011. The new entity, which faced one main competitor and three smaller competitors in the market, had a market share of nearly 40\%. While the French Competition Authority mostly focused on potential anticompetitive effects of the merger, the main concern being the reduction in the number of competitors in competitive tenders, the notifying parties argued that the transaction would generate merger specific efficiency gains. These were claimed to be linked, on the one hand, to the achievement of cost savings in the operation of the networks and, on the other hand, to the possibility of providing a more extensive service offering thanks to the pooling of experience between the parties.

In France, the urban public transport sector is regulated by local authorities (cities or groups of cities) that are in charge of its organization at the local level. In the majority of networks, this task is delegated to a private/public-private operator. Most operators belong to major transport groups. To select a transport operator, the local authority is required to launch a competitive tender procedure in which it specifies the characteristics of the service to be provided (network length, ticket fares, etc.). One of the main choice criterion in the tenders is the level of subsidies asked by the operator to operate the service. Hence, efficiency gains can be a powerful means for operators to succeed in tenders. At the same time, efficiency gains, if reflected in lower subsidies paid to transport operators, reduce taxpayer burden. This is of interest in a sector that is highly subsidized, with commercial revenues 
covering only $30 \%$ of the cost of operating the service.

We study whether efficiency gains actually materialized by performing an ex post evaluation of the merger focusing on its effect on operating costs of local operators belonging to the merging transport groups. Our analysis of efficiency gains is based on a unique and detailed database that provides information on the characteristics of urban transport networks, as well as detailed costs and revenues of urban transport operators, in France over the 2006-2014 period, both before and after the merger. This data is further complemented by a database of competitive tenders for the choice of transport operators taking place between 2004 and 2014. In particular, it contains the identities of the incumbent operator, of the winner of the tender, as well as of other operators submitting offers in the competitive procedure. This database enables us to construct various control groups, using information on the intensity of competition in networks.

We employ a difference-in-differences methodology to study the potential efficiency gains resulting from the merger by comparing the evolutions of operating costs of networks operated by the merged companies with those of networks operated by competing companies. Finding a suitable control group to estimate the causal effects of mergers can be a great challenge in many industries (see, for instance, the discussion made by Nevo and Whinston (2010)). The characteristics of the local public transport industry do seem to be a good field for applying the methodology, as we can easily exploit variations in the conditions across local networks. We consider several control groups in order to control for the possibility that the networks operated by competitors of the merging parties have reacted to the merger. We believe that spillover effects may be an issue only if competitors of the merging parties expected the merging party to become more aggressive in competitive tenders following the realization of merger efficiency gains. They could have reacted strategically by improving their bids in competitive tenders and subsequently decreasing operating costs. Hence the reaction by competitors of the merging parties, if any, is likely to concern contracts signed after the merger. The first control group comprises all the networks managed by the three main competitors of Veolia Transport and Transdev, namely CarPostal, Keolis, and RATP Développement. The second control group accounts for this possible strategic reaction of competitors post merger by including only networks for which the contract for the operation of the urban transport service in a given network was signed prior to the merger. The third control group is more restrictive and comprises only networks where there seems to be no competition from Veolia Transport or Transdev during public tenders. This control group is composed only of networks in which Veolia Transport and Transdev did not submit a bid in tenders for the operation of the transport service throughout the period of our analysis. 
To identify more precisely the impact of the merger on the costs of transport operators, we further explore heterogeneity in the cost effects by exploiting the richness of our data. First, we examine whether the effect of the merger differs between the networks operated by the respective merging groups, Veolia Transport and Transdev. Secondly, we explore whether effects on costs differ depending on the type of regulatory contract type in place (fixed-price or cost-plus). Finally, we also consider the effects of the merger, depending on whether the merging parties were direct local competitors prior to the merger, defined as having networks in the same or neighboring counties (fr. département). We also introduce specifications, in which we remove the years between the announcement of the merger and the closing of the deal as this event window may suffer from contamination of the data around the time of the merger.

In all specifications, our results show that the merger did not result in efficiency gains for the merging parties. Our explanation is that Veolia Transport made its merger decision too quickly, resulting not just in a poorly prepared merger, but also employees and clients reluctant to the merger due to differences in cultures between the two groups. These explanations are highly specific to the case at hand. Hence, we cannot conclude from our results that a change of market structure in the sector of urban transport cannot lead to efficiency gains. Additionally, the role played by the context of the transaction (culture, choice of the target, perception by clients and employees, operational preparation of the merger, etc.) in the lack of materialization of efficiency gains questions whether this aspect should be given more weight by economists in their models and by competition authorities in their analysis of potential effects of mergers.

The ability to generalize our results and comment on the European horizontal merger policy is clearly limited. However, we contribute to a growing number of case studies undertaken by economists that can help determine whether horizontal merger policy is being properly enforced. Most such studies concentrate on impacts of horizontal mergers on prices. A large volume of empirical research directly estimates the effects of large and/or controversial mergers by employing a difference-in-differences methodology. In particular, many studies exploit the growing availability of data and features of the retailing sector to assess large mergers in Europe (e.g. Aguzzoni et al. (2014); Aguzzoni et al. (2016); Allain et al. (2017)) and in the U.S. (e.g. Ashenfelter and Hosken (2010); Ashenfelter et al. (2013); Ashenfelter et al. (2015)). Earlier work applying a similar methodology focused on mergers in major industries, such as airline markets (Borenstein (1990); Kim and Singal (1993)), banking (Focarelli and Panetta (2003)) and petroleum (Hastings (2004); Gilbert and Hastings (2005)). Further, a small literature studies the actual effects of mergers with the aim of assessing the validity of predictions of merger simulation models (see, for 
instance, Peters (2006); Weinberg (2011); Weinberg and Hosken (2013); Friberg and Romahn (2015); Björnerstedt and Verboven (2016)).

Despite the growing number of studies analyzing the price effect of mergers in a variety of industries, still little work exists on the ex post evaluation of mergerspecific efficiency gains. To our knowledge, there exist few studies covering a limited number of sectors that evaluate cost efficiencies from mergers directly. Brito et al. (2013) evaluates the impact of mergers in non-life insurance markets in Portugal through their effect on exercising of market power via coordinated effects and firms' internal efficiency. Its analysis relies on the specification and estimation of a structural model including preferences, technology, and a market equilibrium condition. It shows that following the mergers, there is no evidence of either an increase in market power through coordinated behavior or changes in cost efficiency levels. Kwoka and Pollitt (2010) studies the impact of the merger wave that took place in the U.S. electricity industry by analyzing its impact on operating and total costs in electricity distribution. It employs data envelopment analysis to assess efficiency effects of mergers and concludes, on the basis of its results, that electricity mergers are not consistent with improved cost performance. Dranove and Lindrooth (2003) examines hospital consolidation in the U.S. by focusing on its effect on hospital costs. Cost function estimates of hospitals undergoing consolidation are compared to "pseudo-merger" hospitals chosen based on propensity scores. The empirical strategy is based on the assessment of whether the cost functions of actual mergers are lower than those of pseudo-mergers. It shows that mergers consisting of consolidation of financial reporting and licenses generated cost savings in the 2-4 years following the mergers. Clearly, more retrospective studies are needed to help evaluating the effects of mergers on efficiency gains.

The paper is organized as follows. Section 2 presents the French urban public transport industry and describes the merger under study. Section 3 presents our empirical strategy and section 4 our main empirical analysis, findings, and robustness checks. Section 5 discusses the results and section 6 concludes.

\section{Industry background}

\subsection{Organizational background}

In France, the public authority, comprising cities or group of cities, is responsible for organizing urban public transport in that it has to define, finance, and organize it ${ }^{4}$. It provides a guideline for the organization of public passenger transportation in urban

\footnotetext{
${ }^{4}$ The general principles of the organization of urban public transport in France date back to the Transport Law of 1982 (fr. Loi 82-1153 du 30 décembre 1982 d'orientation des transports intérieurs.
} 
transport areas and establishes the concept of economic and social efficiency by declaring the right to affordable public transport. There exists no national regulator of the sector and transportation is regulated by local authorities. The relevant public authority is left with the choice to organize and provide the service itself or to delegate the relevant responsibilities to a fully private or public-private operator. ${ }^{5}$ Competitive bidding is then compulsory before awarding a contract for the provision of a public service. ${ }^{6}$

Currently, there are approximately 300 transport networks in France, with nearly $90 \%$ of them operated by delegated management (GART (2015)). In delegated management, the local authority chooses an operator to which it entrusts the operation of the service. The key feature of the French model is that the operation of the network is attributed to only one operator, which carries the responsibility of providing the relevant service in the whole urban transport area (see Yvrande-Billon (2006)). The relationship between the operator and the local authority is regulated through a contract in which the local authority specifies the characteristics of the service (ticket fares, number of stops, routes, frequency, output, schedule, quality of service, conditions for subsidizing the service, level of investment, ownership structure, obligations of operators to passengers, etc.) as well as the reimbursement scheme. In most networks, investment in the infrastructure remains the responsibility of the organizing authority, with the local authority owning the rolling stock and infrastructure, which are put at the disposal of the operator. To illustrate, in 2013, 78\% of the rolling stock belonged to organizing authorities (GART (2015)). Hence, operating costs are the relevant measure of long-term efficiency in the specific context of urban transport because operators do not incur capital costs, they only operate the networks.

Urban public transport in France is highly subsidized. The strong social objective of the public policy of urban transport translates into pricing choices that are disconnected not only from total costs, but also from operating costs. As a result, the industry is currently facing strong financial constraints. The ratio of commercial receipts to operating costs has been deteriorating over the years. In 2015, commercial receipts covered, on average, barely $30 \%$ of operating costs (Cour des Comptes (2015)). The remaining operating costs are covered by subsidies from the state,

\footnotetext{
${ }^{5}$ As opposed to the rest of France, the region of Paris (Ile-de-France) has only one authority responsible for organizing urban public transport. It takes its decisions in consultation with dedicated transport carriers (RATP, SNCF, and OPTILE).

${ }^{6}$ Until 1993, the automatic renewal of contracts was a common practice (see Gagnepain and Ivaldi (2002)). The Sapin Law (fr. Loi 93-122 du 29 janvier 1993 relative à la prévention de la corruption et à la transparence de la vie économique et des procédures publiques. made competitive bidding compulsory before awarding a contract for the provision of a public service. The aim of the law is to prevent collusion and corruption, thus enhancing competition between the operators in the industry.
} 
local authorities, and a special transport tax paid by local firms. ${ }^{7}$ Potential merger efficiency gains are of interest in such a highly subsidized industry.

Before the merger, nearly $70 \%$ of the operators were subsidiaries of three major groups, two were private and one semi-public: Keolis, Veolia Transport (hereafter Veolia), and Transdev. In 2009 (prior to the merger), Keolis was owned by SNCF, the French National Railway Company. Veolia was then a subsidiary of the French group Veolia Environment ${ }^{8}$ and Transdev was owned in majority (69.6\%) by the French public financial institution Caisse des Dépôt et Consignations (hereafter CDC).

In addition, three smaller players were already present in the market at that time (RATP Développement, Vectalia France, and Carpostal). RATP Développement (hereafter RATP Dev), owned by RATP, ${ }^{9}$ was created in 2002. Our interviews with local operators suggest that RATP Dev has recently become an important player in the industry, especially in small and middle-sized networks. In addition, two foreign groups were present in the market: Vectalia France and CarPostal France. ${ }^{10}$ The remaining operators were independent or belonged to local and regional transport groups.

Market shares measured by the number of networks of the respective groups are presented in Figure 1. Prior to the merger in 2011, the leading transport group was Keolis (with a market share of nearly 30\%), followed by Veolia (30\%) and Transdev $(15 \%)$.

\subsection{The merger}

Near the end of July 2009, Transdev decided to merge with Veolia. The new entity was expected to be one of the largest transport companies in the world and to be taken public within two years following the merger. The merger was first notified to the European Commission. Subsequently, on August 12, 2010, the European Commission referred it to the French Competition Authority for an examination of the French part of the concentration. The merger was authorized with remedies by

\footnotetext{
${ }^{7}$ This transport tax consists of a local contribution of employers that allows for providing additional funding for urban public transport. It is imposed on both public and private sector employers that employ more than 9 full-time employees within an urban transport area of a population of more than 10,000. It is collected by each urban transport area.

${ }^{8}$ Veolia Environnement S.A. is a French group with global activities in water provision, water sanitation, waste treatment, cleaning and sanitation services, energy services, and transport.

${ }^{9}$ RATP is the operator of urban transport in Paris. It is a public company.

${ }^{10}$ Vectalia France is a subsidiary of the Spanish group Subus and is present in France since 1998. CarPostal France is a subsidiary of the Swiss Group CarPostal Suisse and it operates in France since 2004. The extent of the presence of Vectalia and CarPostal in France was mainly limited to transport areas close to the relevant borders.
} 
Figure 1: Market shares (in number of networks, weighted by their population)

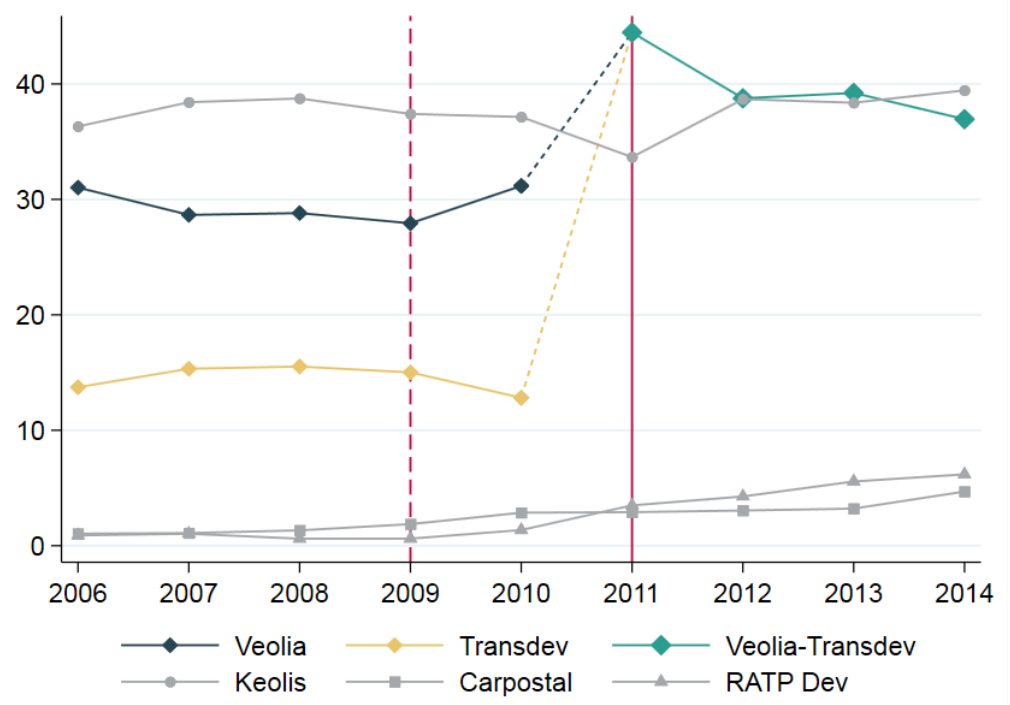

Note: Only groups with at least $5 \%$ market share in 2014 are included in the figure.

the French Competition Authority in December $2010^{11}$ and the final closing took place on March 3, 2011.

The Competition Authority was concerned that the decrease in the number of candidates resulting from the merger could increase the prices of bids submitted in tenders and decrease the quality and diversity of offers, hence the merger was approved by the French Competition Authority subject to several commitments taken by the merging parties.

As in the case of most mergers, the merger between Veolia and Transdev is associated with potential anticompetitive and procompetitive effects. On the one hand, the merger resulted in a decrease in the number of players in the industry and, potentially, in the number of bidders in the relevant tenders, which could foster anticompetitive effects. On the other hand, the merger may have resulted in efficiency gains in the form of a decrease in costs. If these cost efficiencies are passed on to local authorities in the form of more attractive bids in tenders, the merger could have benefited consumers and taxpayers.

\subsection{Potential efficiency gains}

As could be understood from reading the decision of the French Competition Authority, efficiency gains were the key argument put forward by the merging parties to approve the merger. ${ }^{12}$ Indeed, the industry suggests several means by which joining

\footnotetext{
${ }^{11}$ Autorité de la concurrence, Décision 10-DCC-198 du 30 décembre 2010 relative à la création d'une entreprise commune par Veolia Environnement et la CDC.

${ }^{12}$ Concerning efficiency gains, the Competition Authority explained in the decision that the merging parties argued that the merger would create substantial efficiency gains, in particular a
} 
two groups following a merger may give rise to cost efficiencies.

The characteristics of the industry are such that operators have incentives to reduce operating costs. The incentive to reduce costs in this highly subsidized industry comes, on the one hand, from the pressure of competitors in competitive tenders and, on the other hand, from the type of contracts that are used by local authorities. The dominant contract types observed in France are fixed-price and cost-plus contracts. In networks regulated under fixed-price contracts, operators receive subsidies according to their expected operating deficits. Therefore, profits of operators suffer from cost overruns and lower-than-expected revenues. In networks regulated under cost-plus contracts, the organizing authority collects commercial receipts and fully reimburses the operator's operating costs, increased by a predefined additional amount that constitutes the margin of the operator. Under this regulatory scheme, the regulator provides the operator with subsidies to cover its actual deficits. Thus, cost changes do not affect the operator's profits. In the past years, the industry is increasingly moving toward fixed-price contracts, which are high-powered incentive schemes for operators. The proportion of networks regulated under cost-plus contracts has indeed decreased substantially: going from $100 \%$ in the 1970 s, $60 \%$ in the 1980 s, $25 \%$ in the 1990s (Yvrande-Billon (2006)), to only $7 \%$ in 2013 (GART (2015)). Hence, operators are incentivized to decrease costs in order to increase their profits.

There exist several potential sources of operating cost efficiencies in the merger we analyze. Reducing operating costs may come from knowledge sharing between local operators. Local operators are indeed likely to share knowledge at the group level on how to efficiently operate a network. Gagnepain and Aguiar (n.d.) uses an earlier version of our database (until 2001) to show that an operator belonging to an industrial group benefits from the cost reducing activities of the remaining operators of the group. Specifically, knowledge generated by a local operator may be processed by the headquarters of the group and then transmitted to other networks operated by the group. They suggest that cost reducing activities may concern, for instance, R\&D processes, the search for cheaper suppliers, experience in procurement contracts bargaining, or methods in monitoring employees. A merger between two groups may allow methods, procedures, and general knowledge of operators of one group to be passed on to operators belonging to the other. As an example, appropriate staff training may help reduce delays, reduce accidents, and help fight fraud. Knowledge sharing may also concern means of lowering maintenance costs by, for example, finding the right balance between prevention and maintenance.

Further, potential operating costs reductions may come from improved manage-

reduction in operating costs. The Authority, without performing a detailed analysis of efficiency gains, considered that the occurrence of such efficiency gains was not credible enough to counterbalance potential anticompetitive effects from the merger. 
rial efficiency. A change in the managerial policies and procedures imposed on local operators by the new group may move networks of the new entity closer to the best practice of the industry. As an example, better management may help in increasing staff productivity by reducing the rate of absenteeism. The merger may have changed the attitude of the management, thus motivating it and making it more efficient. Cost efficiencies may result in more stable management at the regional and national levels. To our knowledge, management was very unstable in Veolia prior to the merger. Regional and national managers changed very frequently. Since they are responsible for monitoring operating costs of local operators, a more stable managing team could help local operators become more efficient.

Finally, the spread of the specific values and specificities of each group to the other may have reduced operating costs.

\section{Empirical model}

\subsection{Empirical strategy}

We perform a merger evaluation of the merger that took place between Veolia and Transdev by using a difference-in-differences research design (hereafter, DiD), by comparing the evolution of the operating costs of the networks belonging to the merging companies before and after the merger to the evolution of a control group unaffected by the merger. Our focus is whether the merger resulted in cost efficiencies achieved by the new entity.

We estimate the following equation:

$$
\ln \left(C_{n t}\right)=\alpha_{0}+\alpha_{1} \text { Treat }_{i}+\alpha_{2} \text { Post }_{t} * \text { Treat }_{n}+\sum_{i} \beta_{i} X_{\text {int }}+\eta_{t}+\delta_{n}+e_{n t}
$$

where $C_{n t}$ represents the operating costs of network $n$ in year $t$, Post $_{t}$ is a dummy variable taking the value 1 post-merger, Treat ${ }_{n}$ is a dummy variable taking the value one for networks belonging to the treatment group, $X_{n t}$ is a vector of factors other than the merger affecting operating costs, $\delta_{n}$ is a network specific fixed effect $^{13}$, and $e_{n t}$ is the error term. We include year dummies $\eta_{t}$ to account for yearspecific changes in operating costs affecting all operators. $\alpha_{0}, \alpha_{1}, \alpha_{0}$, and $\beta_{i}$ are the coefficients to be estimated. Specifically, $\alpha_{2}$ is the coefficient of interest, it provides a measure of the effect of the merger on the operating costs of the merged entities. The vector $X_{n t}$ includes time-varying variables measured at the network level, which are likely to be a source of omitted variable bias if they are not controlled for, such as the number of seat-kilometers provided by the network or input prices. In all

\footnotetext{
${ }^{13}$ We also consider an estimation without fixed effects. The qualitative results remain unchanged and are available upon request.
} 
estimations, standard errors are clustered at the network level to account for serial correlation, as suggested by Bertrand et al. (2004).

The key assumption behind the use of our identification strategy is that outcomes (operating costs) in the treatment group and control group would have followed, conditional on covariates, parallel trends over time absent the treatment (merger). The ideal control group is such that the variable of interest evolves similarly as in the treatment group with the only difference that it did not experience the treatment. The characteristics of our industry appear to make it a good field for applying the methodology, as we can easily exploit variations in the conditions across local networks and consider a number of potential control groups.

Control group $1(C 1)$. We gathered evidence from CarPostal, Keolis, and RATP Dev, three main other operators in the industry, that are similar with respect to their operating costs and their responses to cost shocks. The first control group is composed of all networks managed by these three main competitors of Veolia and Transdev. ${ }^{14}$

Control group $2(C 2)$. We further account for potential spillovers that may arise if competitors of the merging parties expected the latter to become more aggressive in competitive tenders because of the efficiency gains from the merger. Spillover effects may be an issue only if competitors of the merging parties expected the merging party to become more aggressive in competitive tenders following the realization of merger efficiency gains. They could have reacted strategically by improving their bids in competitive tenders and, subsequently, decreasing operating costs. Hence the reaction of competitors of the merging parties, if any, is likely to concern contracts signed after the merger. The second control group accounts for the possible strategic reaction of competitors post-merger by including only networks in which the contract for the operation of the urban transport service in a given network was signed prior to the merger.

Control group $3(C 3)$. We further exploit information on tender participation to test a more restrictive control group, which is composed only of networks where there seems to be no competition from Veolia or Transdev during public tenders. ${ }^{15}$ We believe that the operators of these networks are unlikely to react to the merger since they are not subject to competition, neither from Veolia nor from Transdev. This control group comprises only networks in which Veolia and Transdev did not submit a bid for tenders for the operation of the transport service throughout the period of our analysis.

\footnotetext{
${ }^{14} \mathrm{We}$ also considered estimations with Keolis separately; the qualitative results remain unchanged.

${ }^{15}$ We also test a control group consisting only of networks where competition in tenders seems to be absent, which is considered to happen in networks that did not see a change in operator since 2005 and in which only one offer was submitted in tenders taking place since 2004. As the parallel trend assumption is not verified for this group, it is excluded from the analysis.
} 
The definitions of the treatment and control groups are summarized in Table $1 .{ }^{16}$

Table 1: Definitions of treatment and control groups

\begin{tabular}{c|c}
\hline Group & Definition \\
\hline Treatment & Networks operated by Veolia or Transdev \\
C1 & Networks operated by Keolis, RATP Dev, or CarPostal \\
C2 & As C1, but only contracts signed before the merger \\
C3 & As C1, but where neither VT nor T submitted a bid \\
\hline
\end{tabular}

Parallel treatment assumption. The key identifying assumption of the DiD estimation method is that had the treatment not been implemented, operating costs of the treatment group and control group would have followed the same evolution, conditional on the control variables included in the regression. To support our identification strategy, we analyze whether the pre-merger common trend assumption is empirically verified in our data. Specifically, we further verify the satisfaction of the parallel trends assumption running a placebo test, as suggested by Autor (2003). It consists of introducing placebo treatments in the equation of interest in all years except one. The following equation is estimated:

$$
\ln \left(C_{n t}\right)=\alpha_{0}+\eta_{t}+\sum_{j \neq 2010} \beta j\left(\text { Treat }_{n} * I(t=j)\right)+\sum_{i} \gamma_{i} X_{\text {int }}+\delta_{n}+e_{n t}
$$

where $C_{n t}$ represents operating costs of network $n$ in year $t, \eta_{t}$ are time-specific dummies, $X_{n t}$ is a vector of factors other than the merger affecting operating costs, $\delta_{n}$ is a network specific fixed effect, Treat $_{n}$ is a dummy variable taking the value 1 for networks belonging to the treatment group, $I(t=j)$ are time dummies for all periods except the period just before the merger, and $e_{n t}$ is the error term. In equation 2 , all coefficients $\beta j$ with $j<2010$ are placebo tests for whether the treatment had an effect on costs between the two groups prior to the merger. This should not happen because if the treatment had an effect before it even occurred, this casts doubt on the parallel trends assumption. Results are presented in section 4

Exogeneity of the merger. The other key assumption in the application of the DiD approach is that the choice to merge with Veolia is not endogenous. The decision by Transdev to merge with another company was not linked in any way to operating costs of networks operated in France or factors influencing them. Transdev belongs to a public financial institution. Its initiative to merge with another

\footnotetext{
${ }^{16}$ We also undertook the analysis on a balanced panel of transport networks that have not seen a change of transport operator in the period of the analysis. The use of this voluntarily restrictive dataset enables us to have networks that remain either in the control or the treatment group over the whole period studied and observe costs for each year and for each network included in the sample. The qualitative results remain unchanged and are available upon request.
} 
French transport company must be understood within this context and the specific situation at that time. Transdev and RATP were not satisfied by the partnership they had commenced in 2002; consequently, RATP wanted to divest its $26 \%$ share of Transdev and develop its subsidiary RATP Dev. Hence, the owner of Transdev, a public institution, started looking for a new partner, with the idea that competition between four French transport groups for contracts abroad was likely to be detrimental to the success of these groups and, therefore, to the French transport industry, and that the creation of a very large group would help win contracts abroad. Thus, the initiative of Transdev was strategic for the development of the French transport industry through the winning of contracts for the operation of networks abroad.

The specific choice of Veolia is not endogenous to the operating costs of networks. According to a report about the merger published in 2016 by the French Court of Audit (Cour des Comptes (2016)), Veolia and Keolis were both serious candidates and the choice of one of them over the other did not prevail in theory. ${ }^{17}$ A comparative examination of the two offers was organized by the owner of Transdev, but this comparative examination was made very quickly. For example the elements of valuation and financial structuring of the transaction were not taken into account in this comparative analysis. According to this report, "subjected to pressure by Veolia Environnement through the media, the CDC did not wish to deepen negotiations.... This choice is probably not independent from the fact that the CDC was also the largest shareholder of Veolia Environnement. The CEO of $C D C$ was in favor of a merger with Veolia. ${ }^{18}$ Thus, Keolis was excluded from the process, with the CDC and Veolia entering into exclusive negotiations regarding the merger of their subsidiaries. This analysis of the French Court of Audit is a soft version of the information found in the news media. Le Parisien, a daily newspaper, explained in 2009 that the general secretary of the French president intervened to tip the balance in favor of Veolia, whose CEO at the time was close to the French president. The left-wing political party PS made a statement to denounce the conditions under which Veolia had been chosen, which seemed to be primarily a political decision sponsored by the French president in order to satisfy the top management of Veolia. ${ }^{19}$ An investigation by the French newspaper Mediapart, published in June 2012, argues that Veolia was chosen by the CDC because of the private relationship between the ex-CEO and non-executive president of Veolia and the CEO of CDC,

\footnotetext{
${ }^{17}$ Regarding operating costs of networks operated in France, a comparison of means of unit costs (operating costs per seat-kilometers) of networks confirms that the two candidates were similar. Average unit operating costs of Keolis and Veolia both amount to $€ 0.032$ per seat-kilometer in 2009.

${ }^{18}$ Cour des Comptes (2016), page 436. Translation from French by the Authors.

${ }^{19}$ The article in the French newspaper Le Parisien is available at: http://www.leparisien.fr/economie/un-geant-du-transport-naitra-de-la-fusion-veolia-transdev23-07-2009-588430.php.
} 
such that the choice of Veolia was mainly motivated by private interests. ${ }^{20}$ Thus, we are strongly convinced that the treatment is not endogenous to operating costs of networks operated in France.

\subsection{Data}

Our study uses a 9-year panel of urban public transport networks in France for the years 2006-2014. The database was created from an annual survey conducted by the Centre d'Études et d'Expertise sur les Risques, l'Environnement, la Mobilité et l'Aménagement (CEREMA) in collaboration with the Groupement des Autorités Responsables de Transport (GART) and the Union des Transports Publics et ferroviaires (UTP). The database contains details on the actors providing the service, the regulatory environment, as well as costs and revenues of operators. ${ }^{21}$

We complement this with an original database gathering tenders for the choice of a transport operator that took place between 2004 and 2014. This information was obtained from press releases and from representatives of organizing authorities. The dataset includes the identity of the transport operators that submitted bids in the tender, the identity of the incumbent transport operator, as well as the identity of the winner of the competitive bidding procedure. This database allows us to introduce one additional control group $(C 3)$, relying on information on participation of groups in tenders.

Our main analysis relies on a larger number of transport networks, dispersed geographically across the country. Details on the number of observations (and networks) included in the respective treatment and control groups are presented in Table 2. Figure 2 then provides their cartographic representation.

Table 2: Number of observations [networks] pre- and post-merger, distinguishing between treatment and control groups

\begin{tabular}{lccc}
\hline Group & All & Pre-merger & Post-merger \\
\hline Treatment & $351[55]$ & $192[50]$ & $159[44]$ \\
C1 & $406[59]$ & $202[49]$ & $204[56]$ \\
C2 & $342[50]$ & $200[48]$ & $142[45]$ \\
C3 & $120[16]$ & $66[15]$ & $54[15]$ \\
\hline
\end{tabular}

Studying the effects of the merger on operating costs requires data on the operating costs, as well as factors, other than the merger, influencing them. Operating

\footnotetext{
${ }^{20}$ The French newspaper Mediapart published an investigation on the merger in June 2012. See "Veolia Transdev : the secrets of a financial mega-disaster," by Laurent Mauduit, June 28, 2012, Mediapart.

${ }^{21}$ For sake of homogeneity across observations, only bus networks serving more than 20,000 inhabitants in the territory of France are selected for the analysis.
} 


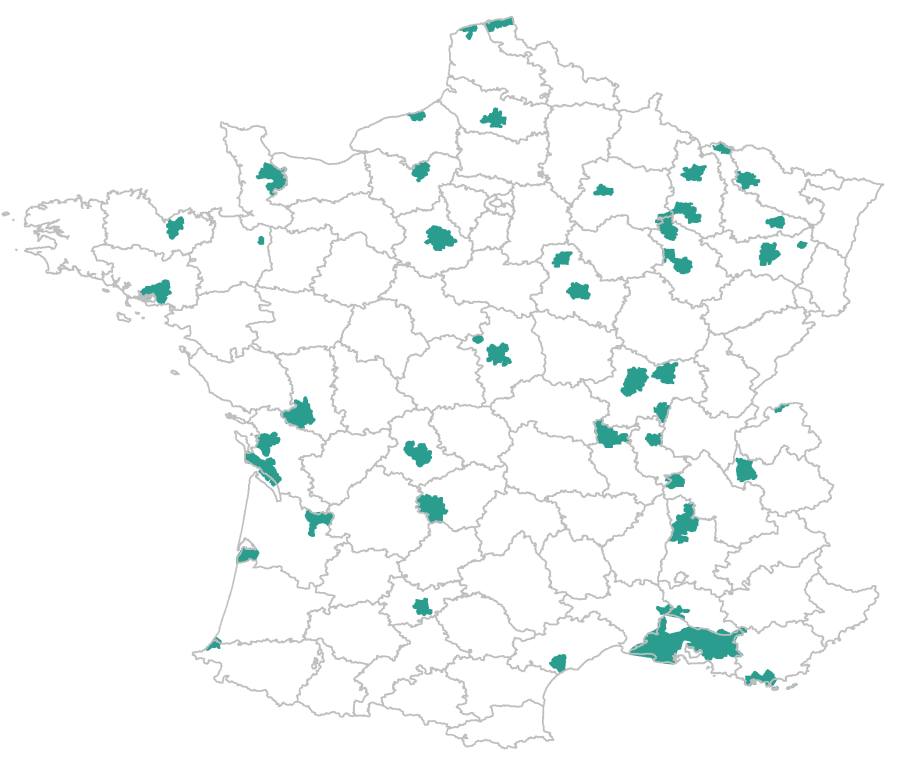

(a) Treatment group

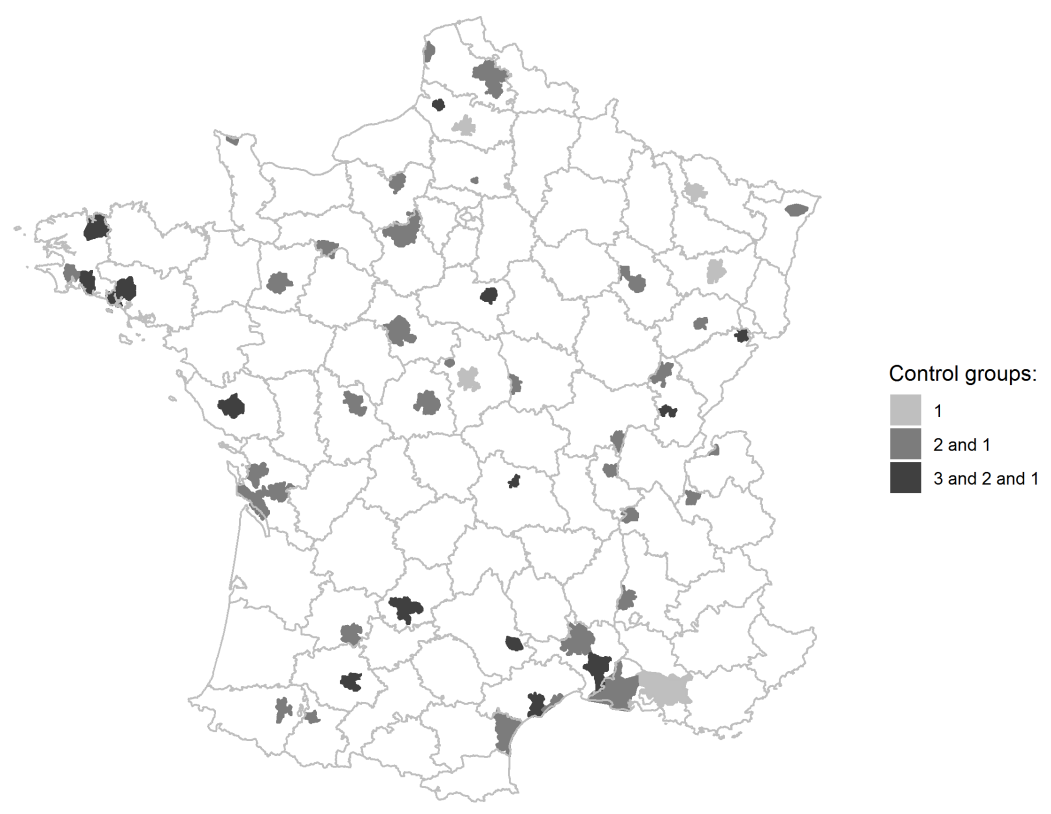

(b) Control groups

Figure 2: Map of transport networks included in the treatment and respective control groups 
costs $C$ are defined as the sum of labor costs and material costs. Output $Y$ is measured by the number of seat-kilometers, i.e. the number of seats available on all buses multiplied by the number of kilometers traveled on all routes. Thus, we use a supply-oriented output variable. Labor price $P L$ is obtained by dividing labor costs by the annual number of employees employed directly by the operator. ${ }^{22}$ Material price $P M$ is obtained by dividing material costs by the total number of vehicles operated by the operator (without including subcontracted vehicles). Since the local authority owns the rolling stock and infrastructure, which are put at the disposal of the operator, the operator does not incur capital costs.

Descriptive statistics of our database, which covers 2006-2014, are presented in Table 3. In the full sample, average operating costs amount to nearly $€ 5 \mathrm{M}$. The average input prices are approximately $€ 37,000$ per employee and $€ 19,000$ of materials per vehicle per year. More than 140 million seat-kilometers are supplied yearly, on average. For the majority of observations (90\%), networks are regulated under fixed-price contracts.

Table 3: Statitics on the dataset - all observations

\begin{tabular}{llcccc}
\hline Variable & Variable Name & Mean & SD & Min. & Max. \\
\hline$C$ & Costs ('000 Euros) & $4,984.8$ & $6,232.5$ & 38.0 & $38,435.6$ \\
$Y$ & Production ('000 seat-kilometers) & $143,831.0$ & $159,790.4$ & 711.5 & $872,391.2$ \\
$P L$ & Wages ('000 Euros per employee) & 37.3 & 6.2 & 20.1 & 80.7 \\
$P M$ & Price of materials ('000 Euros per bus) & 18.5 & 7.1 & 1.7 & 59.7 \\
$F P$ & Fixed-price contracts & 0.9 & 0.3 & 0.0 & 1.0 \\
\hline
\end{tabular}

Table 4 reports the mean values of our variable of interest (operating costs) in the periods prior to and following the merger, separately for our treatment and control groups. We find that, on average, the treatment faces higher operating costs than the control groups. Looking at the difference in costs post- versus pre- merger, on average, yearly costs have increased (yet insignificantly) for all groups considered.

Table 4: Equality of the means prior and post merger

\begin{tabular}{lcccc}
\hline Group & Mean pre-merger & Mean post-merger & Difference & t-statistic \\
\hline Treatment & $5,865.2$ & $7,218.0$ & $1,352.8$ & -1.36 \\
C1 & $4,737.6$ & $5,760.8$ & $1,023.2$ & -1.55 \\
C2 & $4,741.5$ & $5,523.7$ & 782.1 & -1.18 \\
C3 & $5,506.1$ & $6,329.3$ & 823.2 & -0.52 \\
\hline \multicolumn{5}{r}{$p<0.10,{ }^{* *} p<0.05,{ }^{* * *} p<0.01$}
\end{tabular}

\footnotetext{
${ }^{22}$ Labor costs concern employees employed directly by the operator. Consequently, the number of employees does not include the employees of companies to which the operator outsources some activities. Employees of subcontracting companies represent between $6 \%$ and $9 \%$ of the total number of employees of the operator depending on the year considered.
} 


\section{Results}

\subsection{Main results}

The results of estimating equation 1 are presented in Table 5, where the costs of the merging parties are compared to the carefully designed control groups $C 1, C 2$, and $C 3$. We consider two main specifications, gradually controlling for more observable factors of operating costs that could vary over time. In the first (Specification 1), we control only for the size of the network $(\ln (Y))$. In the second (Specification 2), we include wages $(\ln (P L))$ and material costs $(\ln (P M)) .{ }^{23}$ Finally, we introduce an additional specification (Specification $2 \mathrm{w} /$ window) consisting of estimations excluding the years $2009^{24}$ and 2010. This corresponds to the period between the announcement of Transdev wanting to merge and the merger itself. The aim of this test is to rule out the possibility of operating costs of Veolia, Transdev, or its rival groups being affected by the announcement of the merger.

All specifications include fixed effects to account for the time-invariant heterogeneity between networks. This allows for controlling for changes in economic factors that may impact operating costs but are unobservable to the econometrician. In addition, we include time dummies to control for changes in operating costs observed over time, common for all groups. In order to address serial autocorrelation issues, standard errors are clustered by network in all regressions.

For all control groups and specifications considered, the effect on our coefficient of interest (Post-merger $\times$ Treatment) are low in value (ranging from $1.1 \%$ and $4.1 \%$, depending on the specification considered) and insignificant. In addition, the parameters of the remaining covariates introduced in our model under all specifications considered are significant, with the expected sign and magnitude. As expected, a positive variation in output impacts cost positively. Similarly, an increase in labor and material price, ceteris paribus, increases costs. Overall, these results clearly suggest that the merger did not lead to merger-specific cost efficiencies. Our conclusions do not change following the exclusion of the years 2009 and 2010 from the sample. $^{25}$

We verify the satisfaction of the parallel trends assumption running a placebo test, as presented in equation 2. It consists in introducing placebo treatments in

\footnotetext{
${ }^{23} \mathrm{We}$ also consider an alternative specification consisting of estimating a flexible translog cost function to represent the variable cost function. We do not focus on this specification here, as we are interested in an analysis beyond scale efficiencies. Indeed, efficiencies may also come from a reorganization of activities of the merging parties. In any case, results are unchanged by this modification and are available upon request.

${ }^{24}$ We test several alternative time windows, starting at 2007 and 2008 . This does not change our results and conclusions of the analysis remain the same and are available upon request.

${ }^{25}$ We also considered specifications with separately material and labor costs as variables of interest. The qualitative results remain unchanged and are available upon request.
} 
Table 5: Difference-in-differences estimation - main results

\begin{tabular}{|c|c|c|c|c|c|c|c|c|c|}
\hline & \multicolumn{3}{|c|}{ Specification 1} & \multicolumn{3}{|c|}{ Specification 2} & \multicolumn{3}{|c|}{ Specification $2 \mathrm{w} /$ window } \\
\hline & $(\mathrm{C} 1)$ & $(\mathrm{C} 2)$ & (C3) & $(\mathrm{C} 1)$ & $(\mathrm{C} 2)$ & (C3) & $(\mathrm{C} 1)$ & $(\mathrm{C} 2)$ & (C3) \\
\hline \multicolumn{10}{|l|}{ Treatment variables } \\
\hline \multirow[t]{2}{*}{ Post-merger $\times$ Treatment } & 0.038 & 0.035 & 0.033 & 0.040 & 0.040 & 0.011 & 0.038 & 0.041 & 0.017 \\
\hline & {$[0.031]$} & {$[0.030]$} & {$[0.041]$} & {$[0.031]$} & {$[0.029]$} & {$[0.038]$} & {$[0.036]$} & {$[0.036]$} & {$[0.047]$} \\
\hline \multirow[t]{2}{*}{ Treatment } & -0.21 & -0.33 & 0 & -0.19 & -0.31 & 0 & -0.13 & -0.22 & 0 \\
\hline & {$[0.14]$} & {$[0.24]$} & {$[]$.} & {$[0.15]$} & {$[0.25]$} & {$[]$.} & {$[0.12]$} & [0.19] & {$[]$.} \\
\hline \multicolumn{10}{|l|}{ Control variables } \\
\hline \multirow[t]{2}{*}{$\ln (Y)$} & $0.36^{* * *}$ & $0.35^{* * *}$ & $0.13^{*}$ & $0.35^{* * *}$ & $0.34^{* * *}$ & $0.12^{*}$ & $0.35^{* * *}$ & $0.34^{* * *}$ & $0.11^{*}$ \\
\hline & {$[0.11]$} & {$[0.11]$} & {$[0.070]$} & {$[0.11]$} & {$[0.11]$} & {$[0.065]$} & {$[0.11]$} & {$[0.12]$} & {$[0.067]$} \\
\hline \multirow[t]{2}{*}{$\ln (P L)$} & & & & 0.21 & 0.22 & $0.41^{* *}$ & $0.44^{* *}$ & $0.46^{* *}$ & $0.60^{* * *}$ \\
\hline & & & & {$[0.26]$} & {$[0.26]$} & {$[0.20]$} & {$[0.19]$} & {$[0.20]$} & {$[0.17]$} \\
\hline \multirow{2}{*}{$\ln (P M)$} & & & & $0.13^{* * *}$ & $0.13^{* * *}$ & 0.069 & $0.16^{* * *}$ & $0.17^{* * *}$ & $0.093^{*}$ \\
\hline & & & & {$[0.041]$} & {$[0.041]$} & {$[0.066]$} & {$[0.057]$} & {$[0.059]$} & {$[0.048]$} \\
\hline \multirow{2}{*}{ Constant } & $3.76^{* * *}$ & $3.94^{* * *}$ & $6.16^{* * *}$ & $2.79^{* * *}$ & $2.89^{* * *}$ & $4.64^{* * *}$ & $1.93^{*}$ & 1.96 & $4.04^{* * *}$ \\
\hline & {$[1.20]$} & {$[1.22]$} & {$[0.78]$} & {$[0.90]$} & {$[1.00]$} & {$[1.10]$} & {$[1.15]$} & {$[1.21]$} & {$[0.92]$} \\
\hline Fixed effects & yes & yes & yes & yes & yes & yes & yes & yes & yes \\
\hline Clustered SE & yes & yes & yes & yes & yes & yes & yes & yes & yes \\
\hline Year dummies & yes & yes & yes & yes & yes & yes & yes & yes & yes \\
\hline Observations & 757 & 693 & 471 & 757 & 693 & 471 & 595 & 533 & 368 \\
\hline $\mathrm{R}^{2}$ - adjusted & 0.50 & 0.50 & 0.42 & 0.53 & 0.52 & 0.49 & 0.62 & 0.62 & 0.60 \\
\hline
\end{tabular}

the equation of interest in all years except one, for the respective specifications considered in the analysis. The estimated coefficients $\beta j$ are plotted in Figures $3 \mathrm{a}$ to $3 \mathrm{c}$, for the respective control groups considered. On top of verifying whether there is a difference between the two groups before the merger, which is reflected by coefficients $\beta j$ with $j<2010, \beta j$ with $j>2010$ show how the treatment effect evolves over time after the merger. We might expect the treatment effect to quick in as time passes since change can take time to implement after a merger. These graphs show that none of the coefficients are significant (at a $5 \%$ significance level) in the pre-treatment period, confirming the parallel trends assumption. It also shows that we do not observe any significant effect after the merger.

\subsection{Heterogeneous treatment effects}

The fact that we do not observe any significant average result might suggest that our framework fails to take into account some important underlying heterogeneity in the behavior of networks exploited by the merging parties. Consequently, besides estimating the average effect of the merger on operating costs, we also assess whether the effect differs along relevant dimensions of heterogeneity in the network characteristics. These include heterogeneity in the identity of the merging parties, contract type in place, and the closeness of competition.

Firstly, we explore whether there is any underlying heterogeneity in the behavior of networks exploited by the two merging parties, Veolia and Transdev. The term of interest Post-merger $\times$ Treatment is interacted with a dummy variable associated 


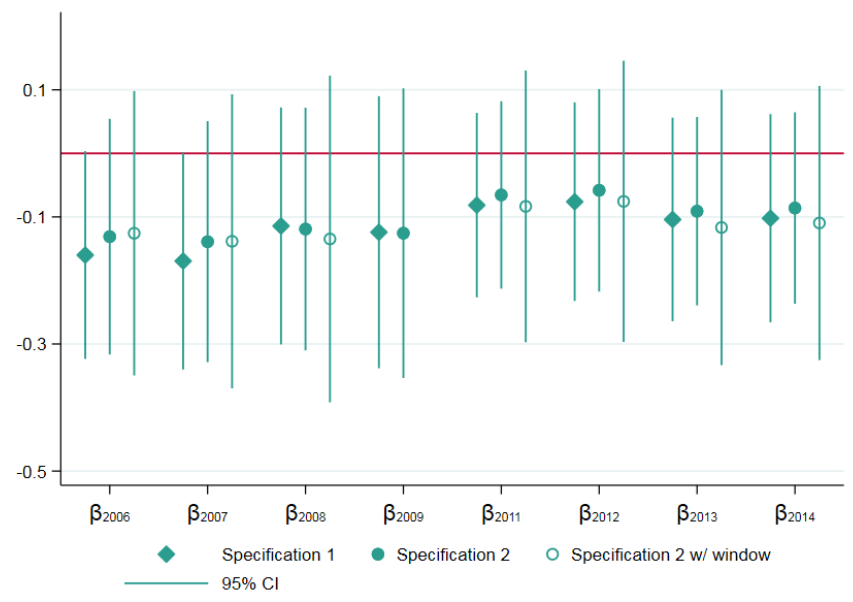

(a) Control group $C 1$ )

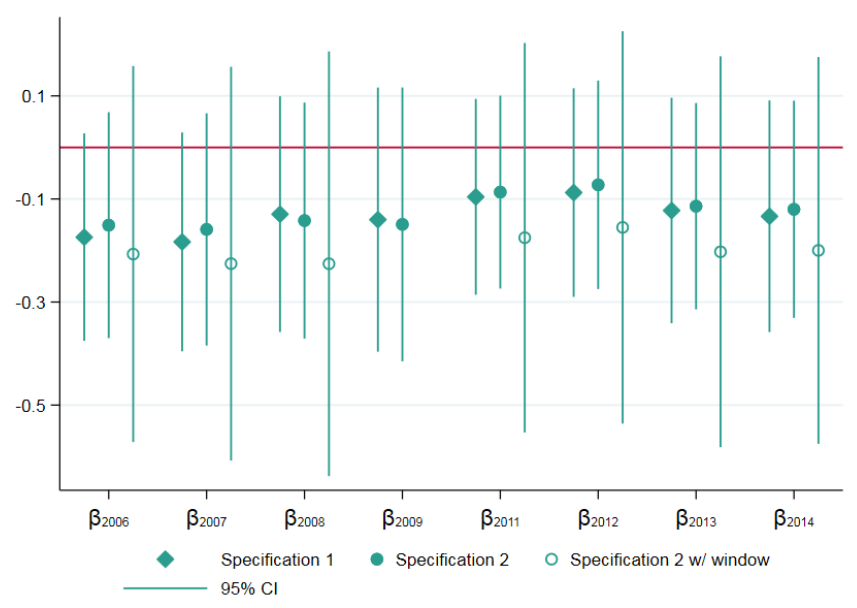

(b) Control group $C 2$

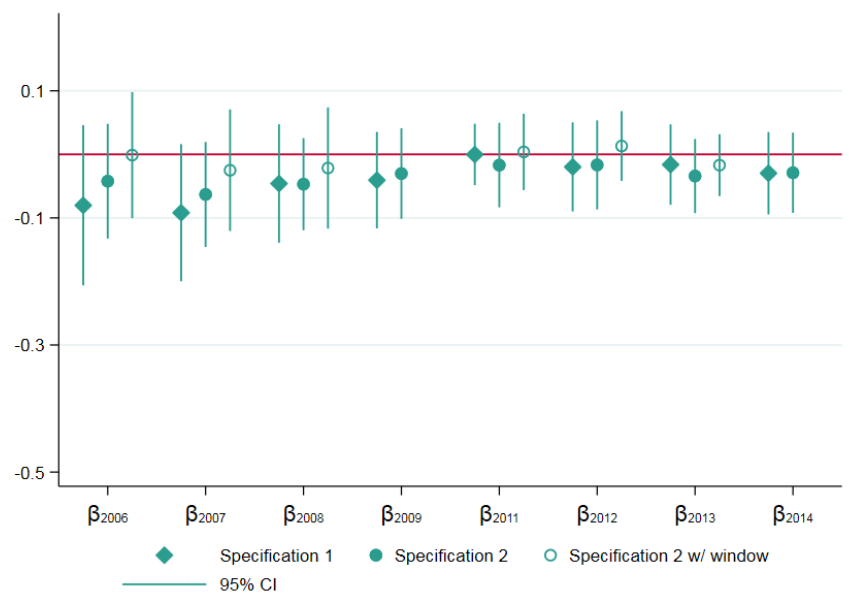

(c) Control group $C 3$

Figure 3: Time relative to the merger for main specifications considered and corresponding to results presented in Table 5). 
to the merging transport group that managed the network prior to the merger, either Veolia or Transdev. To identify the terms of interest, we need to be able to identify which of the merged party's networks were assigned to either Veolia or Trandev before the merger. For this reason, we restrict our treatment to contracts of the merging parties for which we have observations both before and after the merger. The results are reported in Table $6 .^{26}$

Table 6: Difference-in-differences estimation - heterogeneity, by merging party

\begin{tabular}{lccc}
\hline \hline & $(\mathrm{C} 1)$ & $(\mathrm{C} 2)$ & $(\mathrm{C} 3)$ \\
\hline Treatment variables & & & \\
Post-merger $\times$ Treatment $\times$ Veolia & 0.041 & 0.061 & 0.025 \\
& {$[0.048]$} & {$[0.046]$} & {$[0.031]$} \\
Post-merger $\times$ Treatment $\times$ Transdev & -0.014 & 0.0025 & 0.029 \\
& {$[0.022]$} & {$[0.028]$} & {$[0.027]$} \\
Control variables & & & \\
$\ln (Y)$ & $0.18^{* * *}$ & $0.16^{* * *}$ & $0.13^{*}$ \\
& {$[0.059]$} & {$[0.059]$} & {$[0.064]$} \\
$\ln (P L)$ & $0.53^{* * *}$ & $0.55^{* * *}$ & $0.62^{* * *}$ \\
& {$[0.13]$} & {$[0.13]$} & {$[0.15]$} \\
$\ln (P M)$ & $0.15^{* * *}$ & $0.15^{* * *}$ & $0.12^{* *}$ \\
& {$[0.041]$} & {$[0.045]$} & {$[0.046]$} \\
Constant & $3.41^{* * *}$ & $3.54^{* * *}$ & $3.88^{* * * *}$ \\
& {$[0.75]$} & {$[0.77]$} & {$[1.04]$} \\
\hline Fixed effects & yes & yes & yes \\
Clustered SE & yes & yes & yes \\
Year dummies & yes & yes & yes \\
Observations & 642 & 578 & 305 \\
$\mathrm{R}^{2}-$ adjusted & Standard errors in brackets & 0.63 \\
\hline \hline
\end{tabular}

When considering these separate effects, we find no indications of merger efficiency gains, irrespective of the party to the merger considered. In terms of magnitude, the effect for Transdev range from $-1.4 \%$ to $2.9 \%$ and are slightly higher than for Veolia, which range from $0.25 \%$ to $6.3 \%$.

Another potential source of heterogeneity in the behavior of networks may be the contract type in place for a network throughout a contractual period. Gagnepain and Ivaldi (2017) suggest that operating costs may differ depending on the type of regulatory contract type in place (fixed-price or cost-plus). In networks regulated under fixed-price contracts, operators receive subsidies according to their expected operating deficits. Therefore, any changes in operating costs affect their profits.

\footnotetext{
${ }^{26}$ Note that we exclude Treatment from our model, as in the samples considered and within a network, we observe no changes in the belonging to the control or treatment groups that would allow us to identify the coefficient in the presence of network fixed effects.
} 
On the other hand, in networks regulated under cost-plus contracts, the organizing authority collects commercial receipts and fully reimburses the operator's operating costs, increased by a pre-defined additional amount that constitutes the margin of the operator. Under this regulatory scheme, the regulator provides the operator with subsidies to cover its actual operating deficits. Cost changes do not affect the operator's profits. We expect that incentives for cost-reducing activities post-merger may be stronger for networks where fixed-price contracts are in place. We examine whether the effect of the merger differs between fixed-price and cost-plus contracts. Table 7 reports the estimated coefficients for heterogeneous treatment effects. In the first part of the table, the term Post-merger $\times$ Treatment is interacted with the dummy variable associated to the choice of contract type, where $F P$ refers to fixed-price contracts and $C P$ to cost-plus contracts. ${ }^{27}$ In the remaining columns, we consider a sample containing only contracts regulated under FP; approximately $90 \%$ of all observations. ${ }^{28}$

Our results suggest that there is no significant difference in the effect of the merger for networks regulated under cost-plus contracts and for networks regulated under fixed-price contracts. We conclude that the effect of the merger on the merging groups did not differ significantly depending on the contract type in place and remains insignificant.

Finally, we also consider the effects of mergers depending on whether the merging parties were direct local competitors prior to the merger. We introduce two definitions of such networks. The first consists of networks of one of the merging party such that another network was operated by the other merging party in the same county. The second consists of networks of one of the merging party such that another network was operated by the other merging party in the same or adjacent counties. The results of the respective specifications are presented in Table 8.

Accounting for whether the merging parties were direct local competitors prior to the merger, we find no merger-specific efficiency gains.

\footnotetext{
${ }^{27}$ Given that we include network fixed effects in our specifications, the coefficients on $F P$ and $C P$ solely rely on eight changes of contract type in our sample, of which one concerns our treatment group. Thus, our results must be interpreted with caution.

${ }^{28}$ Please note that we do not separately estimate the model for $C P$ contracts, as we face substantial limits in number of observations for this contract type.
} 
Table 7: Difference-in-differences estimation - heterogeneity, by contract type

\begin{tabular}{|c|c|c|c|c|c|c|}
\hline & \multicolumn{3}{|c|}{ Interactions w/ contract type } & \multicolumn{3}{|c|}{ Only FP contracts } \\
\hline & $(\mathrm{C} 1)$ & $(\mathrm{C} 2)$ & (C3) & $(\mathrm{C} 1)$ & $(\mathrm{C} 2)$ & (C3) \\
\hline \multicolumn{7}{|l|}{ Treatment variables } \\
\hline \multirow{2}{*}{ Post-merger $\times$ Treatment $\times C P$} & 0.037 & 0.033 & 0.029 & & & \\
\hline & {$[0.034]$} & {$[0.047]$} & {$[0.024]$} & & & \\
\hline \multirow[t]{2}{*}{ Post-merger $\times$ Treatment $\times F P$} & 0.040 & 0.040 & $0.061^{* *}$ & 0.049 & 0.051 & $0.065^{* *}$ \\
\hline & {$[0.033]$} & {$[0.031]$} & {$[0.030]$} & {$[0.034]$} & {$[0.032]$} & {$[0.032]$} \\
\hline \multirow[t]{2}{*}{ Treatment $\times C P$} & -0.058 & -0.16 & 0 & & & \\
\hline & {$[0.055]$} & {$[0.13]$} & {$[]$.} & & & \\
\hline \multirow[t]{2}{*}{ Treatment $\times F P$} & -0.22 & -0.33 & $-0.033^{* *}$ & -0.22 & -0.35 & 0 \\
\hline & {$[0.21]$} & {$[0.32]$} & {$[0.017]$} & {$[0.24]$} & {$[0.36]$} & {$[]$.} \\
\hline \multirow[t]{2}{*}{$F P$} & $0.16^{*}$ & $0.12^{* * *}$ & 0 & & & \\
\hline & {$[0.084]$} & {$[0.030]$} & {$[]$.} & & & \\
\hline \multicolumn{7}{|l|}{ Control variables } \\
\hline \multirow{2}{*}{$\ln (Y)$} & $0.35^{* * *}$ & $0.34^{* * *}$ & $0.15^{* *}$ & $0.34^{* * *}$ & $0.33^{* * *}$ & $0.15^{*}$ \\
\hline & {$[0.11]$} & {$[0.11]$} & {$[0.070]$} & {$[0.12]$} & {$[0.12]$} & {$[0.074]$} \\
\hline \multirow[t]{2}{*}{$\ln (P L)$} & 0.22 & 0.23 & 0.33 & 0.19 & 0.20 & 0.33 \\
\hline & {$[0.25]$} & {$[0.25]$} & {$[0.22]$} & {$[0.25]$} & {$[0.26]$} & {$[0.23]$} \\
\hline \multirow[t]{2}{*}{$\ln (P M)$} & $0.13^{* * *}$ & $0.13^{* * *}$ & 0.077 & $0.14^{* * *}$ & $0.14^{* * *}$ & 0.078 \\
\hline & {$[0.041]$} & {$[0.044]$} & {$[0.071]$} & {$[0.046]$} & {$[0.049]$} & {$[0.076]$} \\
\hline \multirow[t]{2}{*}{ Constant } & $2.66^{* * *}$ & $2.79^{* * *}$ & $4.77^{* * *}$ & $2.96^{* * *}$ & $3.13^{* * *}$ & $4.69^{* * *}$ \\
\hline & {$[0.89]$} & {$[0.98]$} & {$[1.25]$} & {$[0.95]$} & [1.08] & {$[1.30]$} \\
\hline Fixed effects & yes & yes & yes & yes & yes & yes \\
\hline Clustered SE & yes & yes & yes & yes & yes & yes \\
\hline Year dummies & yes & yes & yes & yes & yes & yes \\
\hline Observations & 757 & 693 & 419 & 687 & 630 & 362 \\
\hline $\mathrm{R}^{2}$ - adjusted & 0.53 & 0.52 & 0.49 & 0.50 & 0.50 & 0.48 \\
\hline
\end{tabular}

Standard errors in brackets

$$
{ }^{*} p<0.10,{ }^{* *} p<0.05,{ }^{* * *} p<0.01
$$


Table 8: Difference-in-differences estimation - heterogeneity, by closeness of competition

\begin{tabular}{|c|c|c|c|c|c|c|}
\hline & \multicolumn{3}{|c|}{ Specification 1} & \multicolumn{3}{|c|}{ Specification 2} \\
\hline & (C1) & $(\mathrm{C} 2)$ & (C3) & $(\mathrm{C} 1)$ & $(\mathrm{C} 2)$ & (C3) \\
\hline \multicolumn{7}{|l|}{ Treatment variables } \\
\hline \multirow[t]{2}{*}{ Post-merger $x$ Treatment $x$ direct } & 0.019 & 0.014 & 0.047 & 0.023 & 0.028 & $0.075^{* *}$ \\
\hline & {$[0.042]$} & {$[0.040]$} & [0.034] & {$[0.028]$} & {$[0.028]$} & [0.029] \\
\hline \multirow[t]{2}{*}{ Post-merger $x$ Treatment $x$ non-direct } & 0.043 & 0.043 & $0.060^{* *}$ & 0.062 & 0.072 & 0.0039 \\
\hline & {$[0.033]$} & {$[0.031]$} & {$[0.030]$} & [0.079] & {$[0.080]$} & {$[0.045]$} \\
\hline \multirow[t]{2}{*}{ Treatment $x$ direct } & 0 & 0 & 0 & -0.020 & 0.0050 & 0 \\
\hline & [.] & [.] & [.] & [0.031] & {$[0.073]$} & [.] \\
\hline \multirow{2}{*}{ Treatment $x$ non-direct } & -0.19 & -0.32 & 0 & -0.36 & -0.41 & 0 \\
\hline & {$[0.15]$} & [0.25] & [.] & {$[0.27]$} & [0.31] & [.] \\
\hline \multicolumn{7}{|l|}{ Control variables } \\
\hline \multirow[t]{2}{*}{$\ln (Y)$} & $0.35^{* * *}$ & $0.34^{* * *}$ & $0.15^{* *}$ & $0.33^{* * *}$ & $0.32^{* * *}$ & $0.14^{* *}$ \\
\hline & {$[0.11]$} & {$[0.11]$} & {$[0.070]$} & {$[0.100]$} & {$[0.11]$} & [0.069] \\
\hline \multirow{2}{*}{$\ln (P L)$} & 0.21 & 0.22 & 0.33 & 0.22 & 0.22 & 0.34 \\
\hline & {$[0.26]$} & {$[0.26]$} & {$[0.22]$} & {$[0.24]$} & {$[0.26]$} & {$[0.22]$} \\
\hline \multirow[t]{2}{*}{$\ln (P M)$} & $0.13^{* * *}$ & $0.13^{* * *}$ & 0.078 & $0.13^{* * *}$ & $0.14^{* * *}$ & 0.071 \\
\hline & [0.041] & [0.041] & {$[0.070]$} & [0.039] & [0.040] & [0.069] \\
\hline \multirow[t]{2}{*}{ Constant } & $2.79^{* * *}$ & $2.88^{* * *}$ & $4.73^{* * *}$ & $2.96^{* * *}$ & $3.00^{* * *}$ & $4.84^{* * *}$ \\
\hline & {$[0.90]$} & {$[0.99]$} & {$[1.24]$} & {$[0.93]$} & {$[1.03]$} & {$[1.21]$} \\
\hline Fixed effects & yes & yes & yes & yes & yes & yes \\
\hline Clustered SE & yes & yes & yes & yes & yes & yes \\
\hline Year dummies & yes & yes & yes & yes & yes & yes \\
\hline Observations & 757 & 693 & 419 & 757 & 693 & 419 \\
\hline $\mathrm{R}^{2}$ - adjusted & 0.52 & 0.52 & 0.49 & 0.55 & 0.54 & 0.50 \\
\hline
\end{tabular}

Standard errors in brackets

${ }^{*} p<0.10,{ }^{* *} p<0.05,{ }^{* * *} p<0.01$ 


\section{Discussion}

Our results clearly demonstrate that the operating costs of networks operated in France by Veolia and Transdev did not decrease following the merger. Can we conclude from this failure to produce efficiency gains that such a change in market structure in the transport sector is not be a way to decrease costs?

To understand our results, we turn to the annual report of the French Court of Audit (Cour des Comptes), published in 2016 (see Cour des Comptes (2016)), which carefully examines the merger used in this study. The title of the report, which is quite compelling, is "A hasty decision, a poorly prepared, and poorly conducted project" [translated by the authors from French]. It appears in the report that the owner of Transdev, CDC, heavily underestimated the difficulties and risks of the operation.

The first salient point is that the choice of Veolia by Transdev was made extremely quickly and, therefore, the project was insufficiently studied and the business plans presented by both Transdev and Veolia were too optimistic (in terms of gasoline price, cost efficiency gains, and activity growth in France). The two candidates, Veolia and Keolis, had only six days to respond to the specifications set out by Transdev. Transdev did not wish to deepen the negotiations with the two candidates and rapidly chose Veolia. This choice was most probably linked to the fact that the owner of Transdev (CDC) was the main shareholder of Veolia Environnement (the owner of Veolia) and that the chief Executive officer of CDC was in favor of a merger with Veolia.

The second salient point is that Transdev minimized the difficulties linked to the compatibility between the models and corporate cultures of the two companies, which were quite different. The trust of Transdev's clients was linked to its belonging to the CDC, a public financial institution, and to proximity management. Concerning Veolia, the business approach was different and relied on the entire group's activities. The ability of the teams to work together was also a key condition for success. Yet Transdev's management indicated in a "contribution to the instruction" dated June 5, 2009, that it was unfavorable to the draft merger with Veolia. Clients were very skeptical about the new company and teams were demotivated from the beginning of the project. This explanation corroborates the management literature, which stresses that culture conflict is a major source of failures of mergers (see, among others, Steigenberger (2017) or Caiazza and T.Volpe (2015) for a review of this literature). In one often cited study, culture is found to be responsible for $30 \%$ of failed integrations (see Dixon (2005)). Notwithstanding, culture is frequently neglected when the benefits of potential mergers are examined. Often, it seems unimportant compared to efficiency gains from combining resources or knowledge, although cultural clashes can completely prevent merger efficiency 
gains from materializing (see Weber and Camerer (2003)).

The third salient point is that the merger was not well prepared, even though it took the companies twenty-one months to obtain approval from the relevant competition authorities. Changes to the transaction were decided one month before the closing, giving no time to shareholders to adapt on the operational side. For example, initially the CEO of Transdev was supposed to become the CEO of the merged company, but this was changed a month before the closing in favor of an externally hired CEO. The choice of the CEO of Veolia to become the COO was also changed. The new CEO, who came from CDC, was proposed by Veolia Environnement. He was recruited with a contract signed with Veolia Environnement. On the operational side, at the time of the closing of the transaction in March 2011, several operational questions were still not resolved. The merger was in fact a juxtaposition of two legal entities and two organizations. For instance, no file on the subject was transmitted to the representative bodies of the workforce, no decision was made on the new brand and logo, on the reorganization of the networks in France and abroad, or on the location of the headquarters of the new group.

The report concludes that: "The merger of Transdev, a CDC subsidiary, with Veolia Transport, a subsidiary and division of Veolia Environnement, was decided hastily, insufficiently studied and conducted in a deficient manner. If corporate mergers are complex processes whose results are frequently disappointing, particularly with regard to valuation and synergies achieved, it is clear that in this case the CDC heavily underestimated the difficulties and risks of the operation. It very quickly favored the choice of Veolia Transport and accepted the accelerated pace desired by Veolia Environnement. In doing so, it was deprived of the opportunity to further analyze the relevance and feasibility of the operation, contrary to the recommendations of the Supervisory Commission and the Minister of the Economy. As a result of this precipitation, the conditions set out in the initial agreement signed on July 22, 2009, have all been called into question at a later date... More generally, this transaction revealed a significant weakness in the governance of the CDC. It is indeed essential that investment or disinvestment decisions on major issues cease to rest solely on the responsibility of the CEO and, as in all entities of this size, effectively involve at the various stages of the decision and of the negotiation the body in charge of supervising the institution and the action of the CEO."29

This analysis of the French Court of Audit provides a convincing explanation of why merger efficiency gains did not materialize. It shows that this failure is highly specific to the case at hand. It also highlights that the specific context in which a merger takes place (justifications for the merger, differences in culture between the companies, perception of the merger by clients and employees, preparation of the

\footnotetext{
${ }^{29}$ Cour des Comptes (2016), pages 454 and 455. Translated by the authors from French.
} 
merger, etc.) are highly relevant dimensions to take into account when assessing the potential impacts of a merger.

\section{Conclusion}

The goal of the analysis presented in this paper is to contribute to the growing literature that evaluates antitrust policy toward horizontal mergers, by studying explicitly merger efficiency gains. We employ a difference-in-differences methodology to study potential merger efficiency gains from a large and widely debated merger that took place in 2011 between Veolia and Transdev in the French urban public transport industry.

There is little evidence in the literature on whether large horizontal mergers result in efficiencies. This gap in the literature is explained by data limitations. Given the particularity of this industry and available data, we are able to introduce a direct test for merger-specific efficiencies.

Our results show that the merger did not lead to any decrease in operating costs for the merging parties. Our study relies on the use of several control groups. It is robust to a great number of robustness checks as well as to the introduction of heterogeneous treatment effects, depending on the identity of the merging party, the contract type in place, and the closeness of competition of local operators.

A possible explanation of why the efficiency gains expected by the parties to the merger did not materialize is that the choice of Veolia was made too hastily, the merger was poorly prepared, and the differences in cultures between the two groups made both clients and employees reluctant to support the merger. The role of context (culture, choice of the target, perception by clients and employees, etc.) in the lack of efficiency gains calls into question whether it should be given more weight by economists in their research and by competition authorities in their ex ante analyses of potential effects of mergers. 


\section{References}

Aguzzoni, L., Argentesi, E., Buccirossi, P., Ciari, L., Duso, T., Tognoni, M. and Vitale, C. (2014), 'A Retrospective Merger Analysis in the U.K. Videogame Market', Journal of Competition Law and Economics 10(4), 933-958.

Aguzzoni, L., Argentesi, E., Ciari, L., Duso, T. and Tognoni, M. (2016), 'Ex Post Merger Evaluation in the U.K. Retail Market for Books', The Journal of Industrial Economics 64(1), 170-200.

Allain, M.-L., Chambolle, C., Turolla, S. and Villas-Boas, S. B. (2017), 'Retail Mergers and Food Prices: Evidence from France', The Journal of Industrial Economics 65(3), 469-682.

Ashenfelter, O. C. and Hosken, D. S. (2010), 'The Effect of Mergers on Consumer Prices: Evidence from Five Mergers on the Enforcement Margin', Journal of Law and Economics 53(3), 417-466.

Ashenfelter, O. C., Hosken, D. S. and Weinberg, M. C. (2013), 'The Price Effects of a Large Merger of Manufacturers: A Case Study of Maytag-Whirlpool', American Economic Journal: Economic Policy 5(1), 239-261.

Ashenfelter, O. C., Hosken, D. S. and Weinberg, M. C. (2015), 'Efficiencies Brewed: Pricing and Consolidation in the US Beer Industry', The RAND Journal of Economics 46(2), 328-361.

Autor, D. (2003), 'Outsourcing at will: The contribution of unjust dismissal doctrine to the growth of employment sourcing', Journal of Labor Economics 21(1), 1-42.

Bertrand, M., Duflo, E. and Mullainathan, S. (2004), 'How Much Should We Trust Differences-in-Differences Estimates?', The Quarterly Journal of Economics 119(1), 249-275.

Björnerstedt, J. and Verboven, F. (2016), 'Does Merger Simulation Work? Evidence from the Swedish Analgesics Market', American Economic Journal: Applied Economics 8(3), 125-164.

Borenstein, S. (1990), 'Airline Mergers, Airport Dominance, and Market Power', American Economic Review 80(2), 400-404.

Brito, D., Pereira, P. and Ramalho, J. J. (2013), 'Mergers, Coordinated Effects and Efficiency in the Portuguese Non-Life Insurance Industry', International Journal of Industrial Organization 31(5), 554-568. 
Caiazza, R. and T.Volpe (2015), 'M\&A process: A Literature Review and Research Agenda', Business Process Management Journal 21(1), 205-220.

Cour des Comptes (2015), Rapport annuel - Les transports publics urbains de voyageurs : un nouvel équilibre à rechercher, Technical report.

Cour des Comptes (2016), Rapport annuel - La fusion Transdev-Veolia Transport: une opération mal conçue, de lourdes pertes à ce jour pour la Caisse des Dépôts et Consignations, Technical report.

Dixon, I. (2005), Culture management and mergers and acquisitions, Society for human resource management case study.

Dranove, D. and Lindrooth, R. (2003), 'Hospital Consolidation and Costs: Another Look at the Evidence', Journal of Health Economics 22, 983-997.

Focarelli, D. and Panetta, F. (2003), 'Are Mergers Beneficial to Consumers? Evidence from the Market for Bank Deposits', The American Economic Review 93(4), 1152-1172.

Friberg, R. and Romahn, A. (2015), 'Divestiture Requirements as a Tool for Competition Policy: A Case from the Swedish Beer Market', International Journal of Industrial Organization 42, 1-18.

Gagnepain, P. and Aguiar, L. (n.d.), Knowledge Spillovers in Cost-Reduction Incentives, mimeo 2013.

Gagnepain, P. and Ivaldi, M. (2002), 'Stochastic Frontiers and Asymmetric Information Models', Journal of Productivity Analysis 18(2), 145-159.

Gagnepain, P. and Ivaldi, M. (2017), 'Economic Efficiency and Political Capture in Public Service Contracts', The Journal of Industrial Economics 65, 1-38.

GART (2015), 'L'année 2013 des transports urbains'.

Gilbert, R. J. and Hastings, J. S. (2005), 'Market Power, Vertical Integration and the Wholesale Price of Gasoline', Journal of Industrial Economics 53(4), 469-492.

Hastings, J. S. (2004), 'Vertical Relationships and Competition in Retail Gasoline Markets: Empirical Evidence from Contract Changes in Southern California', The American Economic Review 94(1), 317-328.

Kim, E. H. and Singal, V. (1993), 'Mergers and Market Power: Evidence from the Airline Industry', The American Economic Review 83(3), 549-569. 
Kwoka, J. and Pollitt, M. (2010), 'Do Mergers Improve Efficiency? Evidence from Restructuring the US Electric Power Sector', International Journal of Industrial Organization 28(6), 645-656.

Nevo, A. and Whinston, M. D. (2010), 'Taking the Dogma out of Econometrics: Structural Modeling and Credible Inference', Journal of Economic Perspectives 24(2), 69-82.

Ormosi, P., Mariuzzo, F. and Havell, R. (2015), A review of merger decisions in the eu: What can we learn from ex-post evaluations?, Technical report, European Commission.

Peters, C. (2006), 'Evaluating the Performance of Merger Simulation: Evidence from the U.S. Airline Industry', The Journal of Law \& Economics 49(2), 627-649.

Steigenberger, N. (2017), 'The Challenge of Integration: A Review of the M\&A Integration Literature', International Journal of Management Reviews 19(4), 408431.

Weber, R. and Camerer, C. (2003), 'Cultural Conflict and Merger Failure: An Experimental Approach', Management Science 49(4), 400-415.

Weinberg, M. C. (2011), 'More Evidence on the Performance of Merger Simulations', The American Economic Review 101(3), 51-55.

Weinberg, M. C. and Hosken, D. (2013), 'Evidence on the Accuracy of Merger Simulations', Review of Economics and Statistics 95(5), 1584-1600.

Yvrande-Billon, A. (2006), 'The Attribution Process of Delegation Contracts in the French Urban Transport Sector: Why Competitive Tendering is a Myth', Annals of Public and Cooperative Economics 77(4), 453-478. 